\title{
Avaliação de Políticas Públicas Culturais - Modelo de Análise da Efetividade da Lei de Incentivo à Cultura
}

\author{
Cultural Public Policy Assessment - model for analysis ou culture incentive law \\ effectiveness
}

Carolina Edom Piccoli, Dra. UFRJ

Professora Assistente, UFRGS

Av. João Pessoa, 52, Centro, Porto Alegre, RS

carolina.piccoli@ufrgs.br

Aracéli Cristina de S. Ferreira, Dra. USP

Professora Titular, UFRJ

Av. Pasteur, 250, Urca, Rio de Janeiro, RJ

araceli@facc.ufrj.br

José Ricardo Maia de Siqueira, Dr. UFRJ

Professor Associado, UFF

Rua Desembargador Ellis Hermydio Figueira, Aterrado, Volta Redonda, RJ ricardomaia1011@gmail.com

\section{Resumo}

Aproximar a contabilidade ao campo das políticas públicas culturais, foi a modesta pretensão da presente pesquisa. Neste sentido, seu objetivo foi desenvolver um modelo de avaliação da efetividade da Lei de Incentivo à Cultura, antiga Lei Rouanet, por meio da avaliação de projetos e das ações anuais da lei. Para isto a abordagem da pesquisa foi qualitativa, classificada como descritiva e documental. Como resultado, a pesquisa desenvolveu dois modelos: um para análise da efetividade de um projeto e outro para análise da efetividade do conjunto de projetos realizados em um determinado ano. Para os dois modelos os indicadores (monetários e quantitativos) foram agrupados em três grupos: (a) Acesso à cultura, (b) Distribuição regional e (c) Indicadores de Viabilidade. Sendo assim, o modelo de avaliação de projetos possui vinte e cinco (25) variáveis envolvidas, para a obtenção e cálculo de dezessete (17) indicadores que servirão de base para análise. Já o modelo de avaliação dos projetos realizados em um determinado ano, que aqui é chamado de análise da lei, possui vinte e seis (26) variáveis envolvidas, para a obtenção e cálculo de doze (12) indicadores. A maioria das variáveis necessárias para o desenvolvimento dos modelos são divulgadas pelo Salic, porém, nem sempre o acesso a estes dados é simples, mas os dados são divulgados. Portanto, por meio dos modelos, é possível identificar, através da junção do resultado destes indicadores se o projeto e as ações da lei em um determinado ano, foram ou não efetivas.

Palavras-Chave: Lei de Incentivo à Cultura. Políticas públicas culturais. Avaliação de efetividade. Indicadores monetários e quantitativos.

\begin{abstract}
To bring accounting closer to the field of cultural public policies was the modest pretension of this research. In this sense, its aimed to develop a model for evaluating the effectiveness of the culture incentive law, through the evaluation of projects and the annual actions of the law. To this end, the research approach was qualitative, classified as descriptive and documentary. As a result, the research developed two models: one to analyze the effectiveness of a project and another to analyze the effectiveness of the of projects carried out in a given year. For both models the indicators (monetary and quantitative) were grouped into three groups: (a) Access
\end{abstract}


to culture, (b) Regional distribution and (c) Viability Indicators Culture. Thus, the project evaluation model has twenty-five (25) variables involved, in order to obtain and calculate seventeen (17) indicators that will serve as a basis for analysis. The evaluation model of projects carried out in a given year, which is called the analysis of the law, has twenty-six (26) variables involved, in order to obtain and calculate twelve (12) indicators. Most of the variables necessary for the development of the models are disclosed by Salic, however, access to this data is not always easy, but it is available. Therefore, through the models, it is possible to identify, through the combination of the result of these indicators, whether or not the project and the actions of the law in a given year, were effective or not.

Keywords: Culture incentive law. Cultural public policies. Effectiveness evaluating. Monetary and quantitative indicators.

\section{INTRODUÇÃO}

A junção das áreas da cultura com a contabilidade é urgente e já se mostra necessária, frente as demandas políticas, econômicas e sociais que o país enfrenta permanentemente. O presente trabalho tem a modesta pretensão de uma aproximação da contabilidade com o campo das políticas públicas culturais, fornecendo subsídios quantitativos para debates mais aprofundados.

Acadêmicos já discutem as políticas públicas culturais adotadas pelo país há alguns anos, desde a criação do Ministério da Cultura, não no que tange à utilização de recursos, mas ao que de fato faz com que o Estado cumpra seu papel à frente da sociedade, no que tange a cultura. As Políticas Públicas Culturais no Brasil e no mundo adotam particularidades territoriais, relacionadas a ritos e costumes dos povos, ou seja, cada país precisa seguir e assegurar à sua população que as especificidades locais sempre serão respeitadas. Neste sentido, a transformação do Ministério da Cultura em uma Secretaria Especial, conforme Medida Provisória 870, de $1^{\circ}$ de janeiro de 2019 (BRASIL, 2019), não torna estas pesquisas menos importantes, ao contrário, são elas, agora, ainda mais necessárias para que se possa construir uma história digna para nosso país. Atualmente a pasta do antigo Ministério da Cultura é atendida por uma secretaria vinculada ao Ministério do Turismo

A conservação, manutenção, geração e disseminação da cultura são direitos garantidos aos cidadãos brasileiros pela Constituição Federal, em seu art. 215: "O Estado garantirá a todos o pleno exercício dos direitos culturais e acesso às fontes da cultura nacional, e apoiará e incentivará a valorização e a difusão das manifestações culturais" (BRASIL, 1988). A mesma constituição também garante a necessidade de preservação do patrimônio histórico brasileiro, conforme o artigo 216.

Bases de dados sobre a cultura ainda estão sendo desenvolvidos, e teve início no Censo de 2010 (INSTITUTO BRASILEIRO DE GEOGRAFIA E ESTATISTICA, 2012), quando foram apresentados alguns indicadores relacionados à cultura. No entanto, somente em 2014 foi divulgado o primeiro estudo com foco na área de financiamento e fomento à cultura, promovido pelo Instituto Brasileiro de Geografia e Estatística (IBGE), o qual apresentou dados estaduais e municipais (IBGE, 2015).

Apesar de inúmeras ferramentas possíveis de se utilizar como estratégia de financiamento da cultura no país, a mais conhecida e discutida atualmente no âmbito federal é a Lei de Incentivo à Cultura, fonte de financiamento através de incentivo fiscal.

Advinda da Lei Sarney (Lei 7.505/86), a qual "permitia a dedução de $10 \%$ do imposto de renda de pessoas físicas e $2 \%$ de pessoas jurídicas para utilização em projetos culturais" (GADELHA, 2015, p. 50), a Lei Rouanet, publicada em 1991, discorre a respeito de financiamento de projetos culturais, regulamentando o Programa Nacional de Apoio à Cultura (Pronac), através de incentivo fiscal (MORAES, 2016). 
Nos últimos anos, e mais intensamente a partir do ano de 2016, devido às diversas crises pelas quais o país vem passando, os debates acerca da Lei Rouanet ficaram mais acalorados, colocando em dúvida sua finalidade e também a lisura do processo, inclusive com a influência de políticos, artistas e da própria Polícia Federal, com a proposta de investigações, operações e CPIs. Apesar de todas as críticas, ainda há o interesse por parte de diversos ramos da economia de que a lei seja mantida, com aprimoramentos.

Assim, em função do crescente interesse em identificar o que ocorre com os valores investidos na lei e como os envolvidos lidam com os recursos e ações, é importante que os procedimentos de controle e transparência sejam sempre aprimorados, não no intuito de dificultar os processos, mas, ao contrário, de expor o que deve ser exposto para a sociedade e de facilitar o acesso a todos aqueles que dela necessitam. Apresenta-se como mister uma adequada avaliação dos investimentos realizados na cultura através da renúncia fiscal decorrente da aplicação da lei de incentivo à cultura (chamada até o ano de 2019, desde a sua criação, de Lei Rouanet).

O presente estudo tem como objetivo elaborar um modelo de avaliação da efetividade da Lei de Incentivo à Cultura, através da avaliação de projetos e das ações anuais da lei. Para que o estudo fosse realizado de forma a compreender senão todas, mas a maioria das áreas do conhecimento envolvidas nesse tema, as seguintes ações foram executadas: (i) identificar modelos de avaliação de políticas públicas em todo o mundo; (ii) verificar, dentre as discussões sobre a Lei de Incentivo à Cultura, se já há alguma sugestão de avaliação; (iii) verificar quais os dados disponíveis sobre a Lei; (iv) construir indicadores que atendam aos objetivos da Lei; (v) unir os indicadores para que se atenda ao principal objetivo deste trabalho.

\section{REFERENCIAL TEÓRICO}

Para a melhor compreensão do desenvolvimento do trabalho, alguns termos e palavras-chave devem ser melhor definidos, a fim de que se enquadrem ao objetivo determinado para a presente pesquisa.

Inicialmente, é importante compreender o que são modelos, para identificar se o formato escolhido é pertinente. O termo modelo pode assumir diversos significados, já que, de acordo com Carlyle (2006), há quatro conceitos possíveis: a representação de alguma coisa; uma descrição esquemática de algum sistema, teoria ou fenômeno; a descrição simplificada de uma entidade ou sistema complexo; e um trabalho preliminar, que serve como base a partir do qual um produto final deve ser fabricado. $\mathrm{O}$ conceito de modelo pode possuir duas abordagens, a da ciência e a do sistema. A abordagem da ciência é a busca por relações entre teorias e dados empíricos, considerando que não serão apresentadas realidades, mas sim recortes da realidade, enquanto a abordagem dos sistemas defende que o modelo é a representação simplificada de um sistema real.

"Essas duas abordagens (ciência e sistema) parecem convergir
para um só ponto, mesmo tendo se manifestado de maneiras
diversas, situam o modelo, como designado a representar uma
realidade, um objeto real, não literalmente, mas de forma
simplificada, possibilitando seu entendimento e tornando-o
mensurável, descritível e observável." (PACHECO; ORTEGA,
2015)

A presente pesquisa tende a assumir o papel de representação da realidade e a considerar a política cultural abordada nesta discussão, bem como os dados provenientes de sua execução.

Também é necessário entender o que é avaliação, para que se descarte a possibilidade de discussão a partir de juízos de valor. Cunha (2006) afirma que a avaliação "é um instrumento importante para a melhoria da eficiência do gasto público, da qualidade da 
gestão e do controle sobre a efetividade da ação do Estado, bem como para divulgação dos resultados do governo". Desta forma, avaliações de políticas públicas são capazes de auxiliar o governo no planejamento e formulação de intervenções, no acompanhamento de suas ações, seus ajustes e reformas, bem como na manutenção ou finalização de determinadas ações.

Imprescindível é também refletir sobre efetividade, pois relaciona-se ao retorno gerado para a sociedade. De acordo com Silva (2007), a aferição dos resultados esperados e não esperados, alcançados na implementação de políticas públicas, é a maior preocupação de uma avaliação de efetividade, que deve responder às seguintes questões: em que medida os objetivos propostos na criação das políticas são ou serão alcançados, quando ela for implementada?; como é o funcionamento do programa?; e por quais motivos os resultados foram ou não atingidos?

O conceito de cultura é amplamente discutido por diversos autores, de diversas áreas. para esta pesquisa, por se tratar de um conceito debatido em âmbito multidisciplinar e mundial, serão desconsiderados quaisquer sinônimos propostos pelo senso comum para cultura, mas será destacado apena o conceito definido pela Mondiacult (1982), haja vista o foco do presente trabalho, a fim de elucidar que a cultura possui necessidade de financiamento público e privado.

Segundo a UNESCO (1982), na Conferência Mundial de Políticas Culturais Mondiacult, o conceito de cultura foi discutido e optou-se por não instituir um conceito restrito, mas considerar características distintas e específicas, de modos e pensamentos da vida de cada pessoa e de cada comunidade. Nesse sentido, cultura engloba a criação e a interpretação artística, bem como a execução, a divulgação e as atividades diversas de uma sociedade, na qual seus membros expressam sua visão de mundo através de criações técnicas e científicas que dominam o ambiente natural.

Porém a cultura possui ligação com o Estado, e a partir disso surge a necessidade do debate sobre políticas culturais. Segundo Schuster (2003), de uma forma mais prática, a política cultural pode ser considerada o conjunto das atividades de um governo destinadas às artes, humanidades e patrimônio. De acordo com Rentschler (2002), a partir de estratégias governamentais, estas atividades promovem a produção, disseminação, comercialização e consumo da arte.

A cultura pública normalmente está associada de forma positiva à identidade e ao patrimônio, à forma como as pessoas definem suas comunidades e se enxergam no mundo e na história. Uma política cultural capaz de oferecer a melhor oportunidade para o apoio público é aquela que se posiciona como parte de uma ampla cultura pública, o que inclui as humanidades, a preservação histórica, a transmissão pública e a educação artística. Essa política cultural ideal seria capaz de promover um senso de continuidade de uma população, com capacidade de definir e apoiar o discurso estético e a criatividade artística (MULCAHY, 2006).

Dentre as ações relacionadas às políticas culturais no Brasil está a Lei de Incentivo à Cultura, anteriormente chamada de Lei Rouanet. A Lei Rouanet (BRASIL, 1991), publicada em 1991, foi precedida pela Lei Sarney, e fez importantes alterações para a regulamentação do incentivo fiscal a projetos culturais, por meio do Programa Nacional de Apoio à Cultura (Pronac). Em vigor desde a data de sua publicação, a lei vem sendo aprimorada através de instruções normativas, sendo a mais recente datada de 23 de abril de 2019. Apesar de inúmeras discussões acerca da lei, este é um programa de incentivo à cultura de maior sucesso e maior visibilidade no país.

Os principais objetivos da Lei de Incentivo à Cultura estão apresentados em seu artigo $1^{\circ}$, onde é definido o Programa Nacional de Apoio à Cultura (Pronac), que tem a finalidade de captar e canalizar recursos para o setor (BRASIL, 1991). O rol destes objetivos está exposto no quadro 6 deste texto. 
Com base nestes objetivos, foram desenvolvidos os modelos de avaliação de efetividade propostos pela presente pesquisa.

\subsection{AVALIAÇÃO DA CULTURA - MODELOS DE BASE}

LLadó e Masó (2012) propuseram um sistema de indicadores para a avaliação de políticas culturais municipais, capaz de fornecer informações para gestão (ações), de detectar possíveis intervenções do governo (estratégias) e de identificar e orientar futuras ações para melhoria das políticas públicas. Através de um estudo de caso, em um município espanhol, as autoras criaram um sistema de indicadores de avaliação, ferramenta não existente no nível das políticas públicas.

A proposta final das autoras revelou um sistema de vinte e seis (26) indicadores quantitativos e trinta e cinco (35) indicadores qualitativos, divididos em sete (7) objetivos: (i) analisar a dotação e as características das instalações e serviços sociais e culturais municipais; (ii) estudar a oferta sociocultural municipal ou o apoio municipal e recursos investidos por entidades locais; (iii) analisar a assistência e as políticas de acesso às atividades socioculturais municipais ou àquelas com suporte municipal; (iv) identificar se os recursos municipais são projetados e investidos em programas que funcionam, a partir da perspectiva do tema; (v) analisar o apoio aos criadores locais e o compromisso municipal de fomentar a criatividade do cidadão; (vi) estudar o compromisso municipal com a diversidade cultural e cívica no município, no uso, criação e expressão de atividades socioculturais; (vii) analisar o apoio municipal que existe para a promoção da coletividade e da participação cidadã.

Van den Hoogen (2014) estudou o impacto da avaliação das políticas culturais locais na Holanda provocado pelo implemento de um sistema orçamentário e pela criação de Comitês de Auditoria local. Este sistema concentra-se nos resultados das políticas, enquanto os comitês de auditoria local são responsáveis por analisar a eficácia e eficiência das políticas municipais. $\mathrm{O}$ autor deteve-se em destacar indicadores quantitativos, agrupados de forma a identificar o Valor da Cultura, Valor Pessoal, Valor Social e Valor secundário.

Barbieri, Partal e Merino (2011) propuseram uma discussão para o desenvolvimento das metodologias de avaliação das políticas culturais, seu valor público e os benefícios ao cidadão. Os autores classificam os indicadores culturais em seis categorias: (i) a melhora do meio ambiente e a recuperação de espaços públicos; (ii) o bem-estar individual e o desenvolvimento pessoal; (iii) o desenvolvimento econômico; (iv) capital social e desenvolvimento comunitário; (v) sobrevivência cultural do meio ambiente; (vi) tamanho e estrutura do setor cultural. Por fim, os autores propuseram doze índices para mensuração do retorno social das políticas culturais.

No Brasil, Vidigal (2013) realizou uma proposta de indicadores para o sistema de informações culturais no Distrito Federal, a fim de realizar análise das políticas públicas locais de fomento, da cartografia de ativos culturais, do cenário socioeconômico desse recorte e de uma rede social entre entes e agentes culturais. Como proposta, foram sugeridos indicadores econômicos e sociais.

Com base nestes cenários, o modelo da presente pesquisa foi desenvolvido, considerando aspectos gerais de cada uma das propostas analisadas anteriormente e as características locais relacionadas ao Brasil.

\section{PROCEDIMENTO METODOLÓGICO}

Quanto à forma de abordagem, a pesquisa caracteriza-se por qualitativa, de acordo com seus objetivos é classificada como descritiva, e com base nos procedimentos técnicos utilizados pode-se afirmar que a pesquisa é documental. Na presente pesquisa, a principal base de dados foi fornecida pelo antigo Ministério da Cultura, atual Secretaria Especial da Cultura. 
Por se tratar de uma pesquisa interdisciplinar, que contempla conteúdos das áreas de Políticas Públicas, Cultura e Contabilidade, a presente pesquisa precisou ser detalhadamente organizada, a fim de que o pesquisador se apropriasse de todos os conceitos necessários para propor o modelo aqui pretendido.

Para que fosse possível realizar uma proposta de modelo, foi necessária a observação dos modelos propostos pela academia para avaliação de políticas públicas culturais, objetivo este atingido no referencial teórico e que deu base para o desenvolvimento do restante da pesquisa. Não foram encontrados trabalhos que avaliassem a aplicação de recursos advindos de leis de incentivo, e, desta forma, foi necessário realizar uma relação entre cada modelo já existente e os objetivos da Lei de Incentivo à Cultura, objeto da presente pesquisa. A pesquisa acerca dos modelos de avaliação de políticas públicas se deu no âmbito do portal de periódicos Capes, já os objetivos da Lei Incentivo à Cultura e as informações sobre suas normativas e procedimentos se deu através do sítio da Secretaria Especial da Cultura.

A análise dos modelos já existentes e dos objetivos da lei revelou que a classificação dos indicadores deveria tomar outro formato, que não o dos objetivos, pois alguns objetivos da lei se sobrepõem, o que tornaria o modelo repetitivo. Desta forma, a partir dessas informações, um novo modelo foi criado, com o aproveitamento dos dados advindos dos modelos anteriores e os objetivos da lei, mas com respeito aos grupos apresentados no desenvolvimento da pesquisa.

Também para o aprimoramento da ferramenta ora apresentada, foi necessária a identificação dos dados disponíveis no sítio do antigo Ministério da Cultura, atual Secretaria Especial da Cultura, para que se pudesse identificar quais informações são de fácil ou difícil acesso; ou seja, o presente modelo tem a intenção de ser facilmente aplicado por qualquer pessoa que acesse os dados sobre a utilização da lei, no SalicNet (2016), portanto, os dados referente aos projetos culturais e à lei, podem ser encontrados no sítio aqui referido.

De posse das informações acima citadas, cada um dos indicadores foi analisado com o intuito de uni-los para a formação do modelo; com os objetivos de cada um claramente estabelecido, foi possível identificar se ainda seria necessária a busca por outras variáveis que pudessem vir a auxiliar o desenvolvimento do mesmo.

A partir deste ponto, foi proposto um rol de indicadores e suas variáveis, que formam o modelo de avaliação da efetividade da Lei de Incentivo à Cultura; deste modo, essas informações puderam proporcionar uma análise através de duas perspectivas: a efetividade do projeto e a efetividade da lei por ano, ou por segmento, ou por região, conforme exposto a seguir.

Para que se pudesse propor um modelo de avaliação eficiente, focado em avaliar a lei como um todo, foi realizada uma simulação com base nos dados de anos anteriores, com o intuito de determinar a avaliação necessária, no presente momento, para os indicadores estabelecidos. Essa simulação foi necessária para que se pudesse estabelecer padrões de comparação para os indicadores, a fim de melhor interpretar os resultados obtidos através deles. Foram coletados dados de 1992 a 2002 para a construção do parâmetro, e a intenção é que, para análises futuras, este parâmetro seja novamente atualizado com dados mais recentes da série histórica.

Para a redação final do texto, os indicadores foram revisados três vezes, e os cálculos reestruturados a mesma quantidade de vezes, para dar maior credibilidade e facilidade no uso do modelo.

Também é importante expor que muito se questionou a realização de um trabalho acerca de uma lei tão criticada e discutida, principalmente nos últimos cinco anos, pela mídia brasileira. Em certo momento, inclusive, houve a reflexão sobre a possibilidade de um trabalho maior, que envolvesse todas as ações decorrentes das políticas públicas do país. No entanto, optou-se por permanecer com o estudo sobre a Lei de Incentivo à Cultura, 
exatamente devido a essas discussões e à necessidade de buscar e divulgar dados e informações confiáveis acerca desta ferramenta presente no país. Ferramenta esta que pode manter o Estado como um dos reguladores de atividades relacionadas à cultura.

\section{CONSTRUÇÃO DO MODELO}

A construção do modelo se deu por meio da realização das seguintes ações: a junção dos objetivos da Lei de Incentivo à Cultura com as ferramentas de avaliação já apresentadas por outros autores; a reorganização destas informações, para que se possa apresentar uma estrutura que se aplique ao objetivo da presente pesquisa; a desvinculação aos objetivos da lei, ajustando possíveis semelhanças entre os objetivos; a criação de categorias de indicadores; e o desenvolvimento de cada um dos indicadores.

\subsection{JUNÇÃO DOS OBJETIVOS DA LEI E MODELOS JÁ EXISTENTES}

Com a finalidade de aproveitar os indicadores já existentes na literatura, as ferramentas já apresentadas foram estudadas e relacionadas aos objetivos da lei. É importante destacar que a maioria das ferramentas encontradas propunham indicadores que são apenas dados, e não conjuntos de informações. Desta forma, poucos indicadores encontrados nos trabalhos anteriores foram utilizados para a presente pesquisa, mas foram utilizados como possibilidade de dados para a criação dos novos indicadores. Conforme abordado no referencial teórico, os autores que propuseram avaliações de políticas culturais estão apresentados no Quadro 1, unidos por seus indicadores e relacionados aos objetivos da lei de incentivo à cultura.

Quadro 1: Junção dos modelos de avaliação relacionados aos objetivos da Lei de Incentivo à Cultura

\begin{tabular}{|c|c|c|c|c|}
\hline $\begin{array}{c}\text { Objetivos Lei de } \\
\text { Incentivo à Cultura }\end{array}$ & Lladó e Masó & Van den Hoogen & $\begin{array}{c}\text { Barbieri, Partal e } \\
\text { Merino }\end{array}$ & Vidigal \\
\hline $\begin{array}{l}\text { I - contribuir para } \\
\text { facilitar, a todos, os } \\
\text { meios para o livre } \\
\text { acesso às fontes da } \\
\text { cultura e o pleno } \\
\text { exercício dos direitos } \\
\text { culturais; }\end{array}$ & $\begin{array}{l}\text { OBJETIVO } 1 \\
\text { OBJETIVO } 3\end{array}$ & $\begin{array}{l}\text { Dados de Valor } \\
\text { Primário, } \\
\text { classificados em } \\
\text { Valor Cultural, } \\
\text { Valor Pessoal, } \\
\text { Alcance de } \\
\text { Instalações } \\
\text { Culturais e Valor } \\
\text { Social }\end{array}$ & $\begin{array}{lr}\text { Indicadores } & \text { de } \\
\text { participação, } & \\
\text { conhecimento } & \text { e } \\
\text { distribuição } & \text { de } \\
\text { atividades } & \end{array}$ & $\begin{array}{l}\text { Indicadores } \\
\text { Econômicos e } \\
\text { sociais, já } \\
\text { relacionados aos } \\
\text { existentes na área } \\
\text { de gestão. }\end{array}$ \\
\hline $\begin{array}{l}\text { II - promover e } \\
\text { estimular a } \\
\text { regionalização da } \\
\text { produção cultural e } \\
\text { artística brasileira, } \\
\text { com valorização de } \\
\text { recursos humanos e } \\
\text { conteúdos locais; }\end{array}$ & $\begin{array}{l}\text { OBJETIVO } 5 \\
\text { OBJETIVO } 7\end{array}$ & $\begin{array}{l}\text { Dados de Valor } \\
\text { Primário, } \\
\text { classificados em } \\
\text { Valor Cultural e } \\
\text { Valor Pessoal }\end{array}$ & $\begin{array}{lr}\text { Indicadores } & \\
\text { relacionados } & \mathrm{a} \\
\text { turismo } & \mathrm{e} \\
\text { participação da } & \text { da } \\
\text { população jovem } & \end{array}$ & $\begin{array}{l}\text { Sem indicadores } \\
\text { para este objetivo }\end{array}$ \\
\hline $\begin{array}{l}\text { III - apoiar, valorizar } \\
\text { e difundir o conjunto } \\
\text { das manifestações } \\
\text { culturais e seus } \\
\text { respectivos criadores; }\end{array}$ & OBJETIVO 2 & $\begin{array}{l}\text { Dados de Valor } \\
\text { Primário, } \\
\text { classificados em } \\
\text { Valor Cultural }\end{array}$ & $\begin{array}{l}\text { Indicadores } \\
\text { relacionados } \quad \text { a } \\
\text { grupos } \quad \text { com } \\
\text { determinadas } \\
\text { características }\end{array}$ & $\begin{array}{l}\text { Indicadores } \\
\text { econômicos e } \\
\text { sociais, já } \\
\text { relacionados aos } \\
\text { existentes na área } \\
\text { de gestão. } \\
\end{array}$ \\
\hline $\begin{array}{l}\text { IV - proteger as } \\
\text { expressões culturais } \\
\text { dos grupos } \\
\text { formadores da } \\
\text { sociedade brasileira e } \\
\text { responsáveis pelo } \\
\text { pluralismo da cultura } \\
\text { nacional; }\end{array}$ & $\begin{array}{l}\text { Sem } \\
\text { indicadores } \\
\text { para este } \\
\text { objetivo. }\end{array}$ & $\begin{array}{l}\text { Dados de Valor } \\
\text { Primário, } \\
\text { classificados em } \\
\text { Valor Social }\end{array}$ & $\begin{array}{l}\text { Indicador } \\
\text { relacionado } \\
\text { comunidades } \\
\text { locais }\end{array}$ & $\begin{array}{l}\text { Sem indicadores } \\
\text { para este objetivo }\end{array}$ \\
\hline
\end{tabular}




\begin{tabular}{|c|c|c|c|c|}
\hline $\begin{array}{l}\text { V - salvaguardar a } \\
\text { sobrevivência e o } \\
\text { florescimento dos } \\
\text { modos de criar, fazer } \\
\text { e viver da sociedade } \\
\text { brasileira; }\end{array}$ & OBJETIVO 4 & $\begin{array}{l}\text { Dados de Valor } \\
\text { Primário, } \\
\text { classificados em } \\
\text { Valor Social }\end{array}$ & $\begin{array}{l}\text { Sem indicadores } \\
\text { para este objetivo }\end{array}$ & $\begin{array}{l}\text { Sem indicadores } \\
\text { para este objetivo }\end{array}$ \\
\hline $\begin{array}{l}\text { VI - preservar os } \\
\text { bens materiais e } \\
\text { imateriais do } \\
\text { patrimônio cultural e } \\
\text { histórico brasileiro; }\end{array}$ & $\begin{array}{l}\text { Sem } \\
\text { indicadores } \\
\text { para este } \\
\text { objetivo }\end{array}$ & $\begin{array}{l}\text { Sem indicadores } \\
\text { para este objetivo }\end{array}$ & $\begin{array}{l}\text { Indicadores } \\
\text { relacionados a } \\
\text { bens do patrimônio } \\
\text { histórico e cultural }\end{array}$ & $\begin{array}{l}\text { Sem indicadores } \\
\text { para este objetivo }\end{array}$ \\
\hline $\begin{array}{l}\text { VII - desenvolver a } \\
\text { consciência } \\
\text { internacional e o } \\
\text { respeito aos valores } \\
\text { culturais de outros } \\
\text { povos ou nações; }\end{array}$ & $\begin{array}{l}\text { Sem } \\
\text { indicadores } \\
\text { para este } \\
\text { objetivo }\end{array}$ & $\begin{array}{l}\text { Sem indicadores } \\
\text { para este objetivo }\end{array}$ & 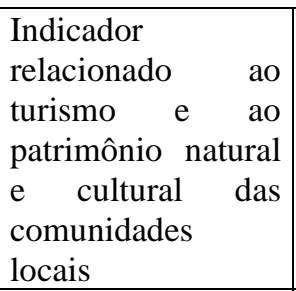 & $\begin{array}{l}\text { Sem indicadores } \\
\text { para este objetivo }\end{array}$ \\
\hline $\begin{array}{l}\text { VIII - estimular a } \\
\text { produção e a difusão } \\
\text { de bens culturais de } \\
\text { valor universal, } \\
\text { formadores e } \\
\text { informadores de } \\
\text { conhecimento, cultura } \\
\text { e memória; }\end{array}$ & $\begin{array}{l}\text { Sem } \\
\text { indicadores } \\
\text { para este } \\
\text { objetivo }\end{array}$ & $\begin{array}{l}\text { Dados de Valor } \\
\text { Primário, } \\
\text { classificados em } \\
\text { Valor Cultural, } \\
\text { Alcance de } \\
\text { Instalações } \\
\text { Culturais e Valor } \\
\text { Social }\end{array}$ & $\begin{array}{l}\text { Indicador } \\
\text { relacionado } \\
\text { inovação social }\end{array}$ & $\begin{array}{l}\text { Sem indicadores } \\
\text { para este objetivo. }\end{array}$ \\
\hline $\begin{array}{l}\text { IX - priorizar o } \\
\text { produto cultural } \\
\text { originário do país. }\end{array}$ & $\begin{array}{c}\text { Sem } \\
\text { indicadores } \\
\text { para este } \\
\text { objetivo }\end{array}$ & & & \\
\hline
\end{tabular}

Fonte: Piccoli, (2019).

\subsection{UMA NOVA PROPOSTA DE INDICADORES}

Conforme apresentado no item anterior, as constatações observadas nos modelos já existentes trouxeram, ao presente trabalho, a necessidade da organização de seus indicadores, inicialmente por grupos que atendam aos objetivos da Lei de Incentivo à Cultura. Levando em conta também as sobreposições dos objetivos da lei, optou-se pela divisão dos indicadores em grupos chamados: "Acesso à Cultura", "Distribuição Regional" e "Indicadores de Viabilidade". Em resumo, o Quadro 2 mostra os três grupos de indicadores criados para este modelo, e destaca quais objetivos da lei serão atendidos por cada um. Também o quadro mostra que os objetivos IV, V e VII não possuirão indicadores, pela dificuldade de avaliação.

Quadro 2: Organização dos grupos de indicadores e os objetivos da Lei de Incentivo à Cultura

\begin{tabular}{|l|c|c|c|c|}
\hline $\begin{array}{l}\text { Grupos de Indicadores/ } \\
\text { Objetivos da Lei de } \\
\text { Incentivo à Cultura }\end{array}$ & $\begin{array}{c}\text { Acesso à } \\
\text { Cultura }\end{array}$ & $\begin{array}{c}\text { Distribuição } \\
\text { Regional }\end{array}$ & $\begin{array}{c}\text { Indicadores de } \\
\text { Viabilidade }\end{array}$ & $\begin{array}{c}\text { Sem } \\
\text { Indicadores }\end{array}$ \\
\hline Objetivo I & & & & \\
\hline Objetivo II & & & & \\
\hline Objetivo III & & & & \\
\hline Objetivo IV & & & & \\
\hline Objetivo V & & & & \\
\hline Objetivo VI & & & & \\
\hline Objetivo VII & & & & \\
\hline Objetivo VIII & & & & \\
\hline
\end{tabular}


Objetivo IX

Fonte: Piccoli, (2019).

Os grupos criados atendem às principais manifestações de interesse relacionados aos próprios objetivos da lei. O grupo de "Acesso à Cultura" apresenta indicadores que mostram quantas pessoas são beneficiadas pela lei e qual a disponibilidade financeira para terem acesso à cultura. O grupo "Distribuição Regional" mostra a distribuição dos recursos e projetos aprovados pela lei no país. Por fim, o grupo "Indicadores de Viabilidade" aborda como, por quem e para quem os recursos são utilizados. A coluna que indica o grupo sem indicadores, está relacionada a objetivos que não teriam indicadores, nos modelos apresentados, úteis para sua avaliação.

\subsection{MODELO DE AVALIAÇÃO DA EFETIVIDADE DA LEI DE INCENTIVO À CULTURA - POR PROJETO}

Apresentamos a seguir o modelo de avaliação da lei, com foco em analisar a efetividade de cada projeto. Para este modelo, foram desenvolvidos dezessete (17) indicadores, que se utilizarão de dados disponíveis ou não no SalicNet.

É importante destacar que o modelo aqui proposto deve ser aplicado em informações históricas, do projeto finalizado, pois a avaliação sugerida é posterior à execução do projeto. A seguir são apresentados os indicadores e como as variáveis envolvidas devem ser tratadas para o cálculo de cada indicador.

\section{Indicadores do grupo Acesso à Cultura:}

1) Ocupação de espaços públicos: dividir a receita com venda de bens e serviços nos espaços públicos pelo valor dos gastos com locação de espaços públicos.

2) Ocupação de espaços privados: dividir a receita com venda de bens e serviços nos espaços privados pelo valor dos gastos com locação de espaços privados.

3) Alcance do projeto - Público: dividir o público total alcançado pelo público estimado.

4) Alcance do projeto - Local: dividir o público total alcançado pela população da região apta a usufruir do produto/ serviço cultural; e dividir o público estimado pela população da região apta a usufruir do produto/ serviço cultural.

5) Valor do projeto por pessoa - Público: dividir o valor de comercialização do bem/ serviço cultural pela divisão entre o valor total captado do projeto e o público total alcançado.

6) Valor do projeto por pessoa: dividir o valor total captado pelo projeto pela quantidade de profissionais remunerados pelo projeto e este resultado dividir pela duração do projeto em meses.

7) Média das remunerações dos profissionais envolvidos no projeto: dividir o valor total das remunerações de profissionais envolvidos o projeto pela quantidade de profissionais remunerados pelo projeto e este resultado dividir pela duração do projeto em meses.

8) Valor do projeto por pessoa - Total: dividir o valor total captado pelo projeto pela soma da quantidade de profissionais remunerados pelo projeto e do público total alcançado; e dividir o valor de comercialização do bem/ serviço cultural pelo resultado anterior.

9) Alcance da divulgação: dividir o valor direcionado à divulgação do projeto pelo público total alcançado; e dividir o valor de comercialização do bem/ serviço cultural pelo resultado anterior.

10) Relações com a sociedade: responder sim ou não para as questões a seguir e atribuir pontuação " 1 " para as respostas sim e "0" para as respostas não. a) $\mathrm{O}$ 
projeto teve ações de acessibilidade? b) O projeto teve ações de democratização do acesso? c) O projeto apresentou os impactos ambientais?

\section{Indicadores do grupo Distribuição Regional:}

1) Regiões atendidas: quantidade de regiões atendidas pelo projeto.

2) Regiões abrangidas: quantidade de regiões considerando a região do proponente, região do tema do projeto, região(ões) dos incentivadores e regiões atendidas pelo projeto.

3) Geração de tributos regionais: dividir o valor de tributos locais pagos pelo projeto - para cada localidade pelo valor total captado do projeto; e dividir o valor de tributos locais pagos pelo projeto - para cada localidade pelo Valor de tributos locais arrecadados - em cada localidade.

Indicadores do grupo Indicadores de Viabilidade:

1) Viabilidade de execução com recursos próprios: dividir o valor da receita total do projeto (receita de vendas e patrocínio sem incentivo) pelo valor total aprovado do projeto.

2) Viabilidade de captação: dividir a receita total do projeto (receita de vendas e patrocínios sem incentivo) pelo valor total captado do projeto.

3) Viabilidade da execução: dividir a receita total do projeto (receita de vendas e patrocínios sem incentivo) pela diferença entre o valor total aprovado do projeto e o valor total captado do projeto.

4) Variação dos orçamentos: dividir o valor total captado do projeto pelo valor total aprovado do projeto; dividir o valor total captado do projeto pelo valor total solicitado pelo projeto.

O Quadro 3 apresenta o resumo das avaliações de cada indicador, os pesos e limites de pontuação de cada grupo. A determinação dos pesos atribuídos aos indicadores possui relação com a quantidade de objetivos da lei que cada grupo atende.

A análise do modelo ocorrerá considerando-se os valores e pesos atribuídos e aplicando-se os dados obtidos sobre o projeto analisado. $\mathrm{O}$ resultado da avaliação deverá ser maior do que quatro e meio $(4,5)$, para considerar o projeto efetivo.

Quadro 3: Resumo do modelo de avaliação da Lei de Incentivo à Cultura por projeto

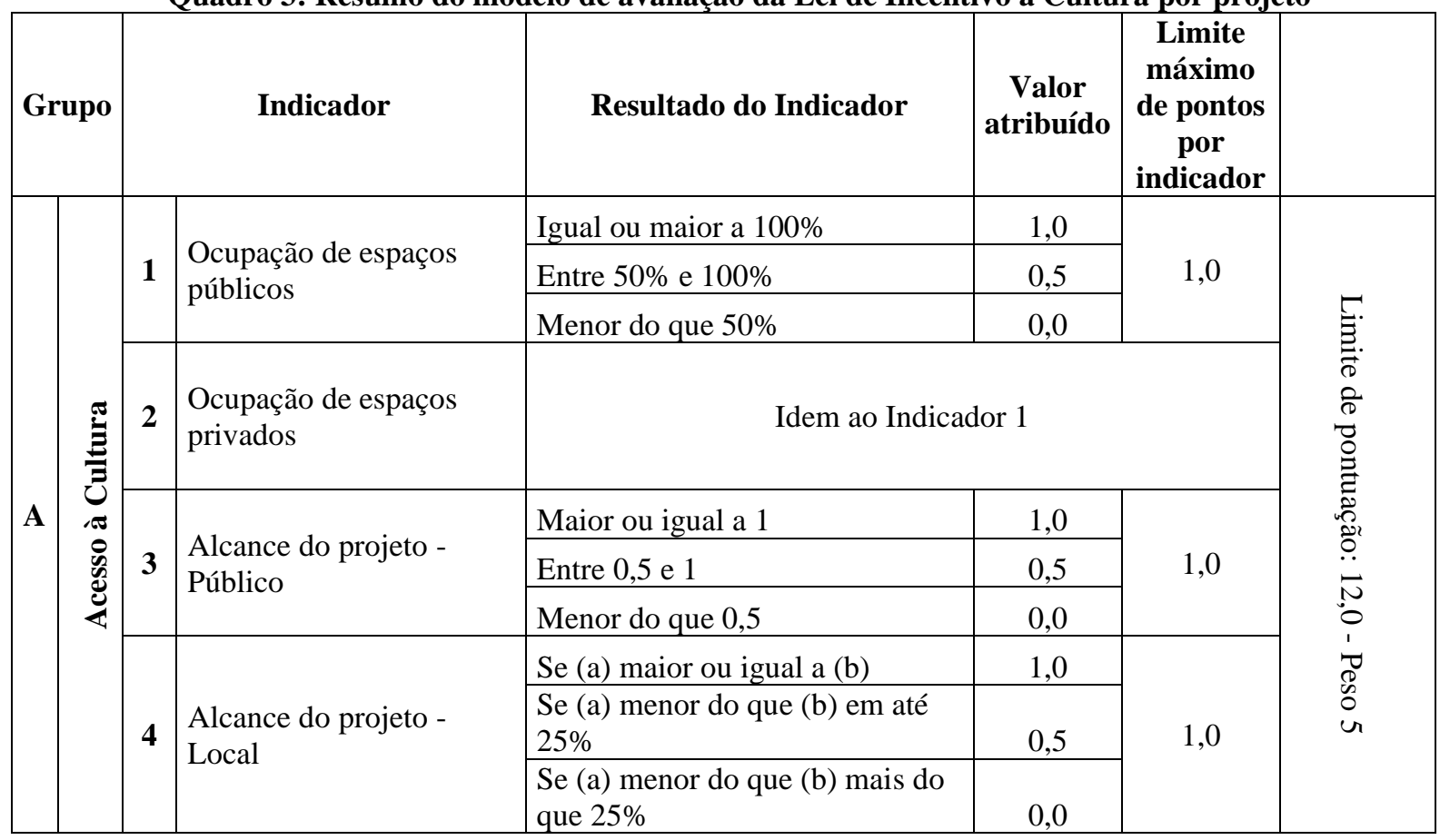




\begin{tabular}{|c|c|c|c|c|c|c|c|}
\hline \multicolumn{2}{|c|}{ Grupo } & \multicolumn{2}{|r|}{ Indicador } & Resultado do Indicador & \multirow[t]{2}{*}{$\begin{array}{l}\text { Valor } \\
\text { atribuído }\end{array}$} & \multirow[t]{2}{*}{$\begin{array}{c}\text { Limite } \\
\text { máximo } \\
\text { de pontos } \\
\text { por } \\
\text { indicador }\end{array}$} & \\
\hline & & 5 & $\begin{array}{l}\text { Valor do projeto por } \\
\text { pessoa - Público }\end{array}$ & Idem ao Indicador 1 & & & \\
\hline & & \multirow{3}{*}{6} & \multirow{3}{*}{$\begin{array}{l}\text { Valor do projeto por } \\
\text { pessoa - Trabalhador }\end{array}$} & Maior do que um salário mínimo & 1,0 & \multirow{3}{*}{1,0} & \\
\hline & & & & Entre meio e um salário mínimo & 0,5 & & \\
\hline & & & & $\begin{array}{l}\text { Menor do que meio salário } \\
\text { mínimo }\end{array}$ & 0,0 & & \\
\hline & & 7 & $\begin{array}{l}\text { Média das remunerações } \\
\text { dos profissionais } \\
\text { envolvidos no projeto }\end{array}$ & \multicolumn{3}{|c|}{ Idem ao Indicador 6} & \\
\hline & & 8 & $\begin{array}{l}\text { Valor do projeto por } \\
\text { pessoa - Total }\end{array}$ & \multicolumn{3}{|c|}{ Idem ao Indicador 1} & \\
\hline & & 9 & Alcance da divulgação & \multicolumn{3}{|c|}{ Idem ao Indicador 1} & \\
\hline & & \multirow{2}{*}{10} & \multirow{2}{*}{\begin{tabular}{|l|} 
Relações com a \\
sociedade (Pontuação \\
para cada item)
\end{tabular}} & Sim & 1,0 & \multirow{2}{*}{3,0} & \\
\hline & & & & Não & 0,0 & & \\
\hline \multirow{8}{*}{ B } & \multirow{8}{*}{ 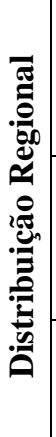 } & \multirow{3}{*}{1} & \multirow{3}{*}{ Regiões atendidas } & Quatro ou cinco regiões & 1,0 & \multirow{3}{*}{1,0} & \multirow{8}{*}{$\begin{array}{ll} & 5 \\
& \\
& 0 \\
0\end{array}$} \\
\hline & & & & Duas ou três regiões & 0,5 & & \\
\hline & & & & Uma região & 0,0 & & \\
\hline & & \multirow{3}{*}{2} & \multirow{3}{*}{ Regiões abrangidas } & Todas as regiões diferentes & 1,0 & \multirow{3}{*}{1,0} & \\
\hline & & & & Ao menos uma região diferente & 0,5 & & \\
\hline & & & & Todas as regiões iguais & 0,0 & & \\
\hline & & \multirow{2}{*}{3} & \multirow{2}{*}{$\begin{array}{l}\text { Geração de tributos } \\
\text { regionais (Pontuação } \\
\text { para cada índice }\end{array}$} & Acima de $0,1 \%$ & 1,0 & \multirow{2}{*}{2,0} & \\
\hline & & & & Abaixo de $0,1 \%$ & 0,0 & & \\
\hline
\end{tabular}




\begin{tabular}{|c|c|c|c|c|c|c|c|}
\hline & & & & Menor do que 0,5 & 1,0 & & 5 \\
\hline & $\frac{\pi}{2}$ & 1 & com recursos próprios & Entre 0,5 e 1 & 0,5 & 1,0 & $\vec{\nabla}$ \\
\hline & 言 & & & Maior ou igual a 1 & 0,0 & & $\vec{b}$ \\
\hline C & i & 2 & Viabilidade de captação & Idem ao Ind & & & $\underset{己}{\stackrel{\Xi}{\Xi}}$ \\
\hline & 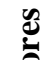 & 3 & Viabilidade de execução & Idem ao Ind & & & 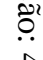 \\
\hline & हु & & & Até $20 \%$ de diferença & 1,0 & & $\stackrel{+}{0}$ \\
\hline & 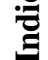 & 4 & Variação dos orçamentos & De $20 \%$ a $40 \%$ de diferença & 0,5 & 1,0 & 8 \\
\hline & & & & Mais do que $40 \%$ de diferença & 0,0 & & $\omega$ \\
\hline
\end{tabular}

Fonte: Piccoli, (2019).

\subsection{MODELO DE AVALIAÇÃO DA EFETIVIDADE DA LEI DE INCENTIVO À CULTURA - GERAL}

Para a realização de uma avaliação geral, é interessante que se façam recortes, a fim de identificar melhor determinados cenários. Recortes relacionados ao tempo e às áreas culturais podem ser os mais efetivos, com menor risco de erro na realização de comparações. Este modelo foi testado pelo recorte de tempo - ano - mas também pode ser segmentado por área ou segmento cultural, apenas com alguns ajustes na ferramenta de análise.

Diferente do modelo aplicado por projeto, o modelo de avaliação geral é composto por doze (12) indicadores, também agrupados pelos mesmos grupos.

Todas as variáveis podem ser encontradas no SalicNet, mesmo que com alguma dificuldade; as duas variáveis externas também são de fácil acesso. A seguir, apresentam-se os indicadores e suas relações com as variáveis e os resumos dos indicadores e avaliações segregados por grupo.

\section{Indicadores do grupo Acesso à Cultura:}

1) Procura pelo incentivo: dividir a quantidade de propostas transformadas em projeto, por ano, pela quantidade de propostas enviadas ao Salic, por ano; dividir a quantidade de projetos aprovados por ano pela quantidade de propostas transformadas em projeto, por ano.

2) Alcance do incentivo: dividir a quantidade de projetos executados por ano pela quantidade de propostas enviadas ao Salic, por ano; dividir a quantidade de projetos executados por ano pela quantidade de projetos aprovados por ano.

3) Proponentes e projetos: dividir a quantidade de propostas transformadas em projeto, por ano, pela quantidade de proponentes, por ano. 
Quadro 4: Resumo do modelo de avaliação da Lei de Incentivo à Cultura - Geral - grupo Acesso à Cultura

\begin{tabular}{|c|c|c|c|c|c|}
\hline & Indicador & Resultado do Indicador & $\begin{array}{c}\text { Valor } \\
\text { atribuído }\end{array}$ & $\begin{array}{c}\text { Limite } \\
\text { máximo } \\
\text { de pontos }\end{array}$ & Obs. \\
\hline \multirow{3}{*}{ 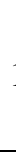 } & \multirow{3}{*}{$\begin{array}{l}\text { Procura pelo incentivo } \\
\text { (Pontuação para cada índice) }\end{array}$} & Igual ou maior a $70 \%$ & 1,0 & \multirow{3}{*}{2,0} & \multirow{7}{*}{ 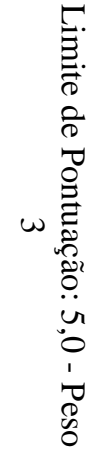 } \\
\hline & & Entre $50 \%$ e $70 \%$ & 0,5 & & \\
\hline & & Menor do que $50 \%$ & 0,0 & & \\
\hline 2 & $\begin{array}{l}\text { Alcance do incentivo } \\
\text { (Pontuação para cada índice) }\end{array}$ & \multicolumn{3}{|c|}{ Idem ao Indicador 1} & \\
\hline \multirow{3}{*}{3} & \multirow{3}{*}{ Proponentes e projetos } & Entre 1,0 e 1,3 & 1,0 & \multirow{3}{*}{1,0} & \\
\hline & & Entre 1,3 e 1,5 & 0,5 & & \\
\hline & & Maior do que 1,5 & 0,0 & & \\
\hline
\end{tabular}

Fonte: Piccoli, (2019).

\section{Indicadores do grupo Distribuição Regional:}

1) Distribuição dos projetos: proporção de participação nos valores aprovados por região, comparada à proporção da população de cada região.

2) Distribuição dos incentivadores: proporção de participação nos valores incentivados por região, comparada ao PIB de cada região.

3) Captação de Recursos: proporção de participação nos valores captados por região, comparada ao PIB de cada região

Quadro 5: Resumo do modelo de avaliação da efetividade da Lei de Incentivo à Cultura - Geral - grupo Distribuição Regional.

\begin{tabular}{|c|c|c|c|c|c|}
\hline & Indicador & Resultado do Indicador & $\begin{array}{l}\text { Valor } \\
\text { atribuído }\end{array}$ & $\begin{array}{c}\text { Limite } \\
\text { máximo } \\
\text { de pontos } \\
\text { por } \\
\text { indicador }\end{array}$ & Obs. \\
\hline \multirow{3}{*}{ 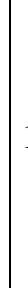 } & \multirow{3}{*}{$\begin{array}{l}\text { Distribuição dos } \\
\text { projetos }\end{array}$} & $\begin{array}{l}\text { Três ou mais percentuais diferem em até } \\
5 \% \text { da proporção da população. }\end{array}$ & 1,0 & \multirow{3}{*}{1,0} & \multirow{5}{*}{ 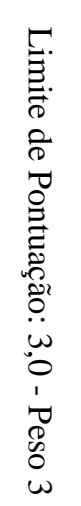 } \\
\hline & & $\begin{array}{l}\text { Três ou mais percentuais diferem em } 5 \% \text { e } \\
20 \% \text { da proporção da população. }\end{array}$ & 0,5 & & \\
\hline & & $\begin{array}{l}\text { Três ou mais percentuais diferem em mais } \\
\text { de } 20 \% \text { da proporção da população. }\end{array}$ & 0,0 & & \\
\hline 2 & $\begin{array}{l}\text { Distribuição dos } \\
\text { incentivadores }\end{array}$ & \multicolumn{3}{|l|}{ Idem ao Indicador 1} & \\
\hline 3 & Captação de recursos & \multicolumn{3}{|l|}{ Idem ao Indicador 1} & \\
\hline
\end{tabular}

Fonte: Piccoli, (2019).

\section{Indicadores do grupo Indicadores de Viabilidade:}

1) Centralização de proponentes Pessoa Física: cálculo da média, moda, mediana, maior valor e menor valor do valor total captado por proponente pessoa física.

2) Centralização de proponentes Pessoa Jurídica: cálculo da média, moda, mediana, maior valor e menor valor do valor total captado por proponente pessoa jurídica.

3) Centralização de incentivadores Pessoa Física: cálculo da média, moda, mediana, maior valor e menor valor do valor total investido por incentivador pessoa física. 
4) Centralização de incentivadores Pessoa Jurídica: cálculo da média, moda, mediana, maior valor e menor valor do valor total investido por incentivador pessoa jurídica.

5) Centralização de projetos por área cultural: proporção de projetos captados por área cultural e de valores captados por área cultural.

6) Variação dos orçamentos: dividir o valor total captado pelo valor total aprovado; dividir o valor total captado pelo valor total solicitado.

Quadro 6: Resumo do modelo de avaliação da Lei de Incentivo à Cultura - Geral - grupo Indicadores de Viabilidade.

\begin{tabular}{|c|c|c|c|c|c|c|}
\hline \multicolumn{2}{|c|}{ Indicador } & \multicolumn{2}{|c|}{ Resultado do Indicador } & \multirow{2}{*}{$\begin{array}{c}\begin{array}{c}\text { Valor } \\
\text { atribuído }\end{array} \\
1,0\end{array}$} & \multirow{2}{*}{$\begin{array}{l}\text { Limite } \\
\text { máximo de } \\
\text { pontos por } \\
\text { indicador }\end{array}$} & \multirow{2}{*}{ Obs. } \\
\hline \multirow{18}{*}{1} & \multirow{18}{*}{$\begin{array}{l}\text { Centralização de } \\
\text { proponentes Pessoa } \\
\text { Física }\end{array}$} & \multirow{3}{*}{$\begin{array}{l}\text { Média por } \\
\text { projeto }\end{array}$} & Acima de $\mathrm{R} \$ 65.000,00$ & & & \\
\hline & & & $\begin{array}{l}\text { Entre } \mathrm{R} \$ 50.000,00 \mathrm{e} \\
\mathrm{R} \$ 65.000,00\end{array}$ & 0,5 & \multirow{17}{*}{6,0} & \multirow{27}{*}{ 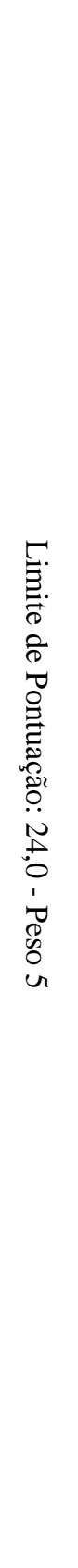 } \\
\hline & & & Abaixo de $\mathrm{R} \$ 50.000,00$ & 0,0 & & \\
\hline & & \multirow{3}{*}{$\begin{array}{l}\text { Média por } \\
\text { proponente }\end{array}$} & Acima de $\mathrm{R} \$ 70.000,00$ & 1,0 & & \\
\hline & & & $\begin{array}{l}\text { Entre } \mathrm{R} \$ 50.000,00 \mathrm{e} \\
\mathrm{R} \$ 70.000,00\end{array}$ & 0,5 & & \\
\hline & & & Abaixo de $\mathrm{R} \$ 50.000,00$ & 0,0 & & \\
\hline & & \multirow{3}{*}{ Moda } & Acima de $\mathrm{R} \$ 30.000,00$ & 1,0 & & \\
\hline & & & $\begin{array}{l}\text { Entre } \mathrm{R} \$ 20.000,00 \mathrm{e} \\
\mathrm{R} \$ 30.000,00\end{array}$ & 0,5 & & \\
\hline & & & Abaixo de $\mathrm{R} \$ 20.000,00$ & 0,0 & & \\
\hline & & & Acima de $\mathrm{R} \$ 45.000,00$ & 1,0 & & \\
\hline & & Mediana & $\begin{array}{l}\text { Entre } \mathrm{R} \$ 40.000,00 \mathrm{e} \\
\mathrm{R} \$ 45.000,00\end{array}$ & 0,5 & & \\
\hline & & & Abaixo de $\mathrm{R} \$ 40.000,00$ & 0,0 & & \\
\hline & & & Acima de $\mathrm{R} \$ 600.000,00$ & 1,0 & & \\
\hline & & Maior Valor & $\begin{array}{l}\text { Entre } \mathrm{R} \$ 300.000,00 \mathrm{e} \\
\mathrm{R} \$ 600.000,00\end{array}$ & 0,5 & & \\
\hline & & & Abaixo de $\mathrm{R} \$ 300.000,00$ & 0,0 & & \\
\hline & & & Acima de $\mathrm{R} \$ 100,00$ & 1,0 & & \\
\hline & & Menor Valor & Entre $\mathrm{R} \$ 50,00$ e $\mathrm{R} \$ 100,00$ & 0,5 & & \\
\hline & & & Abaixo de $\mathrm{R} \$ 50,00$ & 0,0 & & \\
\hline \multirow{10}{*}{2} & \multirow{10}{*}{$\begin{array}{l}\text { Centralização de } \\
\text { proponentes Pessoa } \\
\text { Jurídica }\end{array}$} & & Acima de $\mathrm{R} \$ 300.000,00$ & 1,0 & \multirow{10}{*}{6,0} & \\
\hline & & $\begin{array}{l}\text { Média por } \\
\text { projeto }\end{array}$ & $\begin{array}{l}\text { Entre } \mathrm{R} \$ 250.000,00 \mathrm{e} \\
\mathrm{R} \$ 300.000,00\end{array}$ & 0,5 & & \\
\hline & & & Abaixo de $\mathrm{R} \$ 250.000,00$ & 0,0 & & \\
\hline & & & Acima de $\mathrm{R} \$ 400.000,00$ & 1,0 & & \\
\hline & & $\begin{array}{l}\text { Média por } \\
\text { proponente }\end{array}$ & $\begin{array}{l}\text { Entre } \mathrm{R} \$ 300.000,00 \mathrm{e} \\
\mathrm{R} \$ 400.000,00\end{array}$ & 0,5 & & \\
\hline & & & Abaixo de $\mathrm{R} \$ 300.000,00$ & 0,0 & & \\
\hline & & \multirow{3}{*}{ Moda } & Acima de $\mathrm{R} \$ 100.000,00$ & 1,0 & & \\
\hline & & & $\begin{array}{l}\text { Entre } \mathrm{R} \$ 50.000,00 \mathrm{e} \\
\mathrm{R} \$ 100.000,00\end{array}$ & 0,5 & & \\
\hline & & & Abaixo de $\mathrm{R} \$ 50.000,00$ & 0,0 & & \\
\hline & & Mediana & Acima de $\mathrm{R} \$ 100.000,00$ & 1,0 & & \\
\hline
\end{tabular}




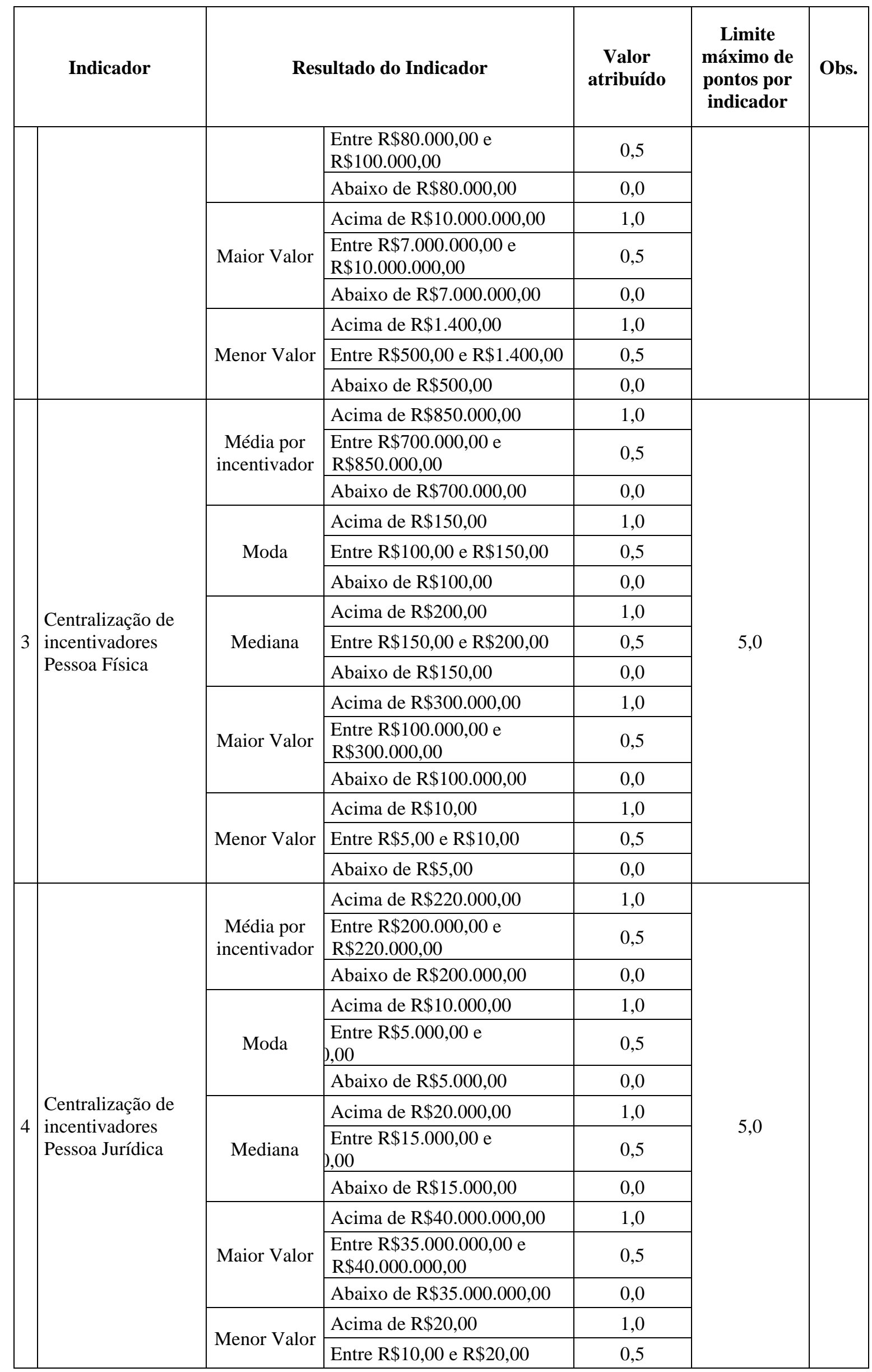




\begin{tabular}{|c|c|c|c|c|c|}
\hline & \multirow[t]{2}{*}{ Indicador } & Resultado do Indicador & \multirow{2}{*}{$\begin{array}{c}\begin{array}{c}\text { Valor } \\
\text { atribuído }\end{array} \\
0,0\end{array}$} & \multirow{2}{*}{$\begin{array}{l}\text { Limite } \\
\text { máximo de } \\
\text { pontos por } \\
\text { indicador }\end{array}$} & \multirow[t]{2}{*}{ Obs. } \\
\hline & & Abaixo de $\mathrm{R} \$ 10,00$ & & & \\
\hline \multirow{3}{*}{5} & \multirow{3}{*}{$\begin{array}{l}\text { Centralização de } \\
\text { projetos por área } \\
\text { cultural }\end{array}$} & Pelo menos 4 áreas com variação inferior a & 1,0 & \multirow{3}{*}{1,0} & \\
\hline & & $\begin{array}{l}\text { Pelo menos } 4 \text { áreas com variação entre } 5 \% \text { e } \\
10 \%\end{array}$ & 0,5 & & \\
\hline & & Maioria das áreas com variação superior a & 0,0 & & \\
\hline \multirow{3}{*}{6} & \multirow{3}{*}{$\begin{array}{l}\text { Variação dos } \\
\text { orçamentos }\end{array}$} & Até $20 \%$ de diferença entre os percentuais & 1,0 & \multirow{3}{*}{1,0} & \\
\hline & & $\begin{array}{l}\text { De } 20 \% \text { a } 40 \% \text { de diferença entre os } \\
\text { percentuais }\end{array}$ & 0,5 & & \\
\hline & & $\begin{array}{l}\text { Acima de } 40 \% \text { de diferença entre os } \\
\text { percentuais }\end{array}$ & 0,0 & & \\
\hline
\end{tabular}

Fonte: Piccoli, (2019).

A análise do modelo ocorrerá considerando-se os valores e os pesos atribuídos, conforme exposto nos Quadros 15, 17 e 20 e aplicando-se os dados obtidos sobre o ano analisado. O resultado da avaliação deverá ser maior do que quatro e meio $(4,5)$ para considerar a lei efetiva, no período analisado. Cabe novamente destacar que outros parâmetros podem ser utilizados para adaptar este modelo a outros agrupamentos.

Em desenvolvimento, tanto no campo das políticas, como no campo da avaliação destas políticas esta prudência na avaliação torna-se relevante. $O$ formato de avaliação proposto, pode ser reavaliado e reestruturado, já que se trata de uma primeira proposta, desta forma, considerações específicas e modelos matemáticos podem ser inseridos para que se tenha uma proposta com maior robustez.

\section{CONSIDERAÇÕES FINAIS}

A verificação de quais as possibilidades de se avaliar uma política pública cultural, com alcance significativo em um país de dimensões continentais foi um dos resultados encontrados através da presente pesquisa.

A Lei de Incentivo à Cultura, principal política cultural de renúncia fiscal no país, carece de discussão e avaliação, foco deste estudo. Com a ferramenta aqui proposta é possível verificar se a lei e seus projetos são efetivos. Cabe aqui destacar, que inicialmente, a proposta da presente pesquisa seria analisar a efetividade da lei, mas devido as observações realizadas no decorrer da pesquisa, optou-se por propor dois modelos: um que se refere à avaliação da lei em um espaço temporal, neste caso o ano e, um que se refere à avaliação de um projeto realizado através da lei.

O modelo de prestação de contas à sociedade, para a divulgação das informações sobre a Lei de Incentivo à Cultura, atualmente, é o banco de dados que também serve como interface de inclusão e avaliação dos projetos, mas que não oferece um tratamento dos dados, sendo assim base para processamento de informações e não uma prestação de contas à sociedade. Apesar de estar disponível através da internet, os dados não são facilmente encontrados, bem como dados finais, sobre os projetos, dificilmente são divulgados pela rede.

Desta forma, o objetivo geral da presente pesquisa foi atingido, ou seja, fora aqui apresentado um modelo de avaliação da efetividade da Lei de Incentivo à Cultura, através da avaliação de projetos e das ações anuais da Lei. Os objetivos específicos também foram desenvolvidos, acerca do que segue. Foram identificados modelos de avaliação de políticas públicas, aqui representados pelos trabalhos de Araújo e Rodrigues (2017) e Souza (2006). 
Mais especificamente, os trabalhos que orientaram a presente pesquisa foram os referente a avaliação de políticas públicas culturais, nos quais foram estudados os trabalhos de LLadó e Masó (2012), Van den Hoogen (2014), Barbieri, Partal e Merino (2011) e Vidigal (2013). Estes modelos foram a base para a concepção do modelo aqui proposto.

Quadro 7: Características de modelo de avaliação da efetividade da Lei de Incentivo à Cultura proposto na presente pesquisa

\begin{tabular}{|c|c|c|}
\hline & $\begin{array}{c}\text { Modelo para avaliação da Lei } \\
\text { por Ano }\end{array}$ & $\begin{array}{c}\text { Modelo para Avaliação da Lei por } \\
\text { Projeto }\end{array}$ \\
\hline $\begin{array}{l}\text { Quantidade de indicadores no grupo } \\
\text { Acesso à Cultura }\end{array}$ & 3 & 10 \\
\hline $\begin{array}{l}\text { Quantidade de indicadores no grupo } \\
\text { Distribuição Regional }\end{array}$ & 3 & 3 \\
\hline $\begin{array}{l}\text { Quantidade de indicadores no grupo } \\
\text { Indicadores de Viabilidade }\end{array}$ & 6 & 4 \\
\hline Quantidade Total de indicadores & 12 & 17 \\
\hline Acesso aos dados & $\begin{array}{l}\text { Todas as variáveis, para o } \\
\text { cálculo dos indicadores são } \\
\text { divulgadas. }\end{array}$ & $\begin{array}{l}\text { Algumas variáveis para cálculo dos } \\
\text { indicadores são de posse apenas do } \\
\text { proponente, ou da CNIC, e não são } \\
\text { divulgados. }\end{array}$ \\
\hline $\begin{array}{l}\text { Quantidade de variáveis necessárias } \\
\text { para cálculo dos indicadores }\end{array}$ & 26 & 25 \\
\hline $\begin{array}{l}\text { Quantidade de variáveis externas ao } \\
\text { Salic }\end{array}$ & 2 & 3 \\
\hline
\end{tabular}

Fonte: Piccoli, (2019).

O Quadro 7, apresenta resumidamente algumas características dos modelos propostos pela presente pesquisa.

Importante destacar, que o modelo aqui desenvolvido para avaliação de projetos, deve respeitar as peculiaridades de cada projeto, e para a verificação de projetos das áreas de Museus e Memória e Patrimônio Histórico e Cultural, o modelo deve receber alguns ajustes para ser melhor aplicado.

\section{REFERÊNCIAS}

ARAÚJO, L.; RODRIGUES, M. D. L. Modelos de análise das políticas públicas. Sociologia, Problemas e Práticas, v. 83, p. 11-35, 2017.

BARBIERI, N.; PARTAL, A.; MERINO, E. Nuevas políticas, nuevas miradas y metodologías Nuevas políticas, nuevas miradas y metodologías de las políticas culturales? Papers revista de sociología, n. 96, p. 477-500, 2011.

BRASIL. Constituição 1988. Constituição da República Federativa do Brasil. Brasília: Câmara dos Deputados, Edições Câmara, 1988. Disponível em: <http://www.planalto.gov.br/ccivil_03/constituicao/ConstituicaoCompilado.htm>. Acesso em: 15 jan. 2016.

BRASIL. Lei 8.313, de 23 de dezembro de 1991. Brasília: República Federativa do Brasil, 1991. Disponível em: <http://www.planalto.gov.br/ccivil_03/leis/L8313cons.htm>. Acesso em: 29 mar. 2016.

BRASIL. MEDIDA PROVISÓRIA No 870, DE $1^{\circ}$ DE JANEIRO DE 2019. Brasília: [s.n.].

CARLYLE, A. CARLYLE, Allyson. Understanding FRBR as a conceptual model: FRBR and 
the bibliographic universe. Library Resources \& Technical Services, v. 50, n. 4, p. 264-273, 2006. Library Resources \& Technical Services, v. 50, n. 4, p. 264-273, 2006.

CUNHA, C. Avaliação de Políticas Públicas e Programas Governamentais: tendências recentes e experiências no Brasil. George Washington University, p. 1-41, 2006.

GADELHA, R. Produção cultural: configurações e paradoxos. Fortaleza: Armazém da Cultura, 2015.

IBGE. Perfil doe estados e dos municípios brasileiros: cultura: 2014. RIO DE JANEIRO: [s.n.]. v. 39

INSTITUTO BRASILEIRO DE GEOGRAFIA E ESTATISTICA. Geociências - IBGE :: Instituto Brasileiro de Geografia e Estatística. 2012.

LLADÓ, A. P.; MASÓ, P. S. Sistema de indicadores para políticas municipales culturales: una herramienta de evaluación. Revista de Metodologia de Ciencias Sociales, n. 24, p. 117$140,2012$.

MULCAHY, K. Cultural Policy: Definitions and Theoretical Approaches. The Journal of Arts Management, Law, and Society, v. 35, n. 4, p. 319-330, 2006.

PACHECO, K. L.; ORTEGA, C. D. Origen del modelo FRBR. Biblios: Revista de Bibliotecología y Ciencias de la Información, v. 60, n. 60, p. 63-75, 2015.

PICCOLI, C. E. Avaliação de políticas públicas culturais: um modelo de análise da efetividade da lei Rouanet. [s.1.] Universidade Federal do Rio de Janeiro, UFRJ, 2019.

RENTSCHLER, R. The entrepreneurial arts leader: cultural policy, change and reinvention. Brisbane: Univesity of Queensland Press, 2002.

SALICNET. Sistema de apoio às leis de incentivo à cultura. Disponível em: <http://sistemas.cultura.gov.br/salicnet/Salicnet/Salicnet.php>. Acesso em: 22 jan. 2016.

SCHUSTER, J. M. D. Mapping state cultural policy: The state of Washington. Chicago: University of Chicago, Cultural Policy Center, 2003.

SILVA, P. B. et al. Sistema de Informações e Indicadores Culturais. n. Iii, 2007.

SOUZA, C. Políticas Públicas: uma revisão da literatura. Political Science, v. 8, n. 2003, p. 20-45, 2006.

UNESCO. Informe Final. CONFERÊNCIA MUNDIAL DE POLÍTICAS CULTURAIS MONDIACULT. Anais...CIDADE DO MÉXICO: 1982Disponível em: <http://unesdoc.unesco.org/images/0005/000525/052505sb.pdf>. Acesso em: 4 jul. 2016.

VAN DEN HOOGEN, Q. L. New local cultural policy evaluation methods in the Netherlands: status and perspectives. International Journal of Cultural Policy, v. 20, n. 5, p. 613-636, 2014. 
VIDIGAL, G. P. Informações e indicadores culturais: caminho para o aperfeiçoamento da dinâmica de controle social e gestão de políticas públicas no Distrito Federal. IV SEMINÁRIO INTERNACIONAL - POLÍTICAS CULTURAIS - 16 a 18 de outubro/2013 Setor de Políticas Culturais - Fundação Casa de Rui Barbosa - Rio de Janeiro - Brasil. Anais...2013 